\title{
Aggression, Politeness, and Abstract Adversaries
}

\section{Catherine Hundleby}

\author{
Department of Philosophy \& CRRAR \\ University of Windsor \\ Windsor, $O N$ \\ Canada N9B 3P4 \\ hundleby@uwindsor.ca
}

\begin{abstract}
Trudy Govier argues in The Philosophy of Argument that adversariality in argumentation can be kept to a necessary minimum. On her account, politeness can limit the ancillary adversariality of hostile culture but a degree of logical opposition will remain part of argumentation, and perhaps all reasoning. Argumentation cannot be purified by politeness in the way she hopes, nor does reasoning even in the discursive context of argumentation demand opposition. Such hopes assume an idealized politeness free from gender, and reasoners with inhuman or at least highly privileged capabilities and no need to learn from others or share understanding.
\end{abstract}

\begin{abstract}
Trudy Govier défend dans The Philosophy of Argument que l'esprit d'opposition dans l'argumentation peut se maintenir à un minimum nécessaire. Selon son compte rendu, la politesse peut limiter l'esprit d'opposition auxiliaire d'une culture hostile, mais un certain degré d'opposition logique reste un aspect de l'argumentation, et peut-être de tout raisonnement. La politesse ne peut pas purifier l'argumentation de la façon qu'elle espère et le raisonnement dans le contexte discursif de l'argumentation n'exige pas une opposition. Ses espoirs supposent une politesse idéalisée détachée des sexes, et des raisonneurs doués de capacités inhumaines ou au moins très privilégiées et sans aucun besoin d'apprendre des autres ou de partager leur compréhension.
\end{abstract}

Keywords: Trudy Govier; abstract; adversary; aggression; argumentation; feminist; ideal; opposition; politeness; rationality. 


\section{Introduction}

Trudy Govier's 1999 book The Philosophy of Argument provides an extensive response to the feminist critiques of adversarial assumptions about argumentation. Govier defends an adversarial orientation of argumentation both for its cognitive necessity and role in critical thinking and for its political fruitfulness. Govier's exposition of how adversariality or opposing positions in argumentation support the value of controversy demands feminist attention, because controversy is part and parcel of feminism.

Govier introduces a fruitful distinction of "minimal adversariality" constituted by taking up an opposing position from "ancillary adversariality," the culture of aggression and hostility often associated with argumentation. She shares a distaste for that culture with other feminists and other argumentation theorists, but she values minimally adversarial discourse because controversy depends on it.

I will explain Govier's position that politeness provides a hedge against the discursive hostility and aggressive emotionality that constitute ancillary adversariality but argue that politeness cannot suffice. It reflects and thus reinforces gendered (and perhaps other unjustified forms of) social dominance. While we-all people and perhaps especially feminists - need a theory of argumentation that can address controversy and lead us through hostile entanglements, we must not obscure the possibility and fruitfulness of alternate modes of argumentation and reasoning. We may exchange reasons without opposing each other's ideas - never mind opposing each other personally. Adversariality is not necessary or even ideal for argumentation, despite its value for democratic politics and critical thinking. It only seems ideal if we neglect the gendered realities of discourse and the limitations of human cognition.

(C) Catherine Hundleby. Informal Logic, Vol. 33, No. 2 (2013), pp. 238-262. 


\section{Catherine Hundleby}

\section{Ancillary adversariality and rational persuasion}

Govier recognizes that many of the demands emerging from the feminist critique of masculine standards in philosophy and argumentation accord with the direction taken by informal logic movement. Both orientations suggest that education in logic and critical the thinking "should not: be primarily in formal logic; model all arguments as deductive; cavalierly apply generalizations to particular cases; dichotomize reason and emotion; or ignore relationships" (p. 52). She argues that the proper operation of reason in argumentation suffers from aggressive emotions and the culture of "ancillary adversariality" that feminists maintain have masculine associations making them more accessible to men and more accepted from men. Adversarial and aggressive metaphors can foster interpersonal aggression, encouraging people to slide into arguing against each other when they disagree rather than just questioning each other's ideas. Adversarial structures in law, politics, and debate, and the personal stake we often have in our own views (p. 50) heighten the likelihood that opposing opinions will slip into aggressive modes that interfere with rational exchange.

Both feminists and informal logicians develop nonadversarial metaphors for argumentation: "build a case, explore a topic, or think through a problem" (p. 9). Yet, many philosophers - and other reasoners as this is part of the common culture of argumentation - still use metaphors of cutting, capture, trouncing, skewering, and other violent and militaristic language to describe successes and failures in argumentation. In response to feminist and other critiques, those who actually work on the topics of argumentative strength and weakness tend to eschew such language, because of the ideological baggage it brings with it, especially the militaristic and eristic (aiming to win) metaphors.

Govier holds out hope that the void left from removing interpersonal aggression, the harsh language, fraught emotion, "strident repetition[,] and loud voices," can fill with respect through people engaging each other as rational agents by appealing to reason and

(C) Catherine Hundleby. Informal Logic, Vol. 33, No. 2 (2013), pp. 238-262. 
evidence. She argues that persuasion can be a deeply respectful enterprise when the means are rational:

The other person is addressed as a rational being, as a person with beliefs and values of his own, as one who thinks and is capable of changing his beliefs on the basis of reasons and evidence. To present someone with an argument is to attend to his or her mind and thinking processes and to do so in a non-manipulative way. It is to honestly acknowledge differences of opinion and belief, not to skirt over them, hide them, or seek to avoid them...to show respect for [arguers] as autonomous thoughtful people. (p. 8)

Govier contrasts rational persuasion more generally with the coercive means having residual presence in "slogans, loaded terminology, or visual imagery" (from the elipsis in previous quotation). The common language of argumentation reflects assumptions that may run deep in our models and norms of argument, but that are outmoded. Conflict, contest, or battle need not result from disagreement; metaphors of defense and victory may be "dead" ( $p$. 54).

Language does often change its meaning and metaphors lose certain resonances; for instance, the misogynist history behind "rule of thumb" does not taint that very useful expression. Yet, the adversarial language of argumentation expresses models and norms that remain lively because of the way militarism and emotional aggression define masculinity in many cultures-especially the dominant culture of Euro-American, white, able-bodied, heteromasculinity, and the conflation of aggression and domination with both masculinity and success (Moulton 1983).

\footnotetext{
${ }^{1}$ I suspect intentional irony here from Govier.

(C) Catherine Hundleby. Informal Logic, Vol. 33, No. 2 (2013), pp. 238-262.
} 


\section{Catherine Hundleby}

\section{Aggression, politeness and gender}

Govier argues that "adversariality is not necessarily confrontational" which is to say that it can be "kept to a logical, and polite minimum," to bare opposition and respectful objection (which describes epistemological opposition) (p. 55). Politeness provides background conditions for argumentation practices also in Douglas Walton's theory of presumptive argumentation, as a source for argumentation schemes that guide reasoning based on specific types of presumptions (1996, pp. xi, 39, 42). Walton (2007, p. 77) takes politeness to be codified by Paul Grice's conversational maxims that encourage conversation to be collaborative rather than adversarial (Walton 2007, p. xvii). Recent research on politeness, however, reveals that it will not suffice as a hedge against aggressive behaviour. Some people's aggression, especially men's, operates as part of polite discourse, endorsing specific forms of rough-housing, both verbal and physical. (I speak of "women" and "men" as a shorthand to refer to people of any age gendered feminine and masculine. $)^{2}$ Politeness institutionalizes rather than moderates certain aggressive tendencies in argumentation, creating gendered power strata in discourse, and preventing metaphors of war and aggression from losing their confrontational implications.

The demands of politeness separate men and women in almost all cultures. In the dominant white able-bodied middle-class heterosexual, Euro-American culture that tends to override other attendant identities and cultures, norms of politeness tend to be more severe and restrictive for women, requiring greater passivity and conformity. And yet women appear immature, irrational, or unserious to the extent that they are "small, timid in manner, have high voices, speak with qualifications and tonalities of uncertainty,

\footnotetext{
${ }^{2}$ New research suggests that the stereotypes that guide our discursive interactions may racialize people in the same terms that define gender, at least in the U.S.A. (Galinsky, A., Hall, E., and Cudd, A. (forthcoming 2013) in Psychological Science). The intersectionality (how different forms of oppression impact on each other) of psychological bias and stereotypes remains mostly neglected and in need of work.
}

(C) Catherine Hundleby. Informal Logic, Vol. 33, No. 2 (2013), pp. 238-262. 
dress in a feminine style connoting prettiness, a desire to please, non-seriousness, etc." Govier recognizes (p. 31). Discursively, women's politeness strategies in Euro-American cultures include various markers of subordinate status that at the same time function to elicit cooperation, including tag questions such as "don't you think?," diminutives ("tiny bit"), and euphemisms (Burrow, p. 247). Such demands undermine women's ability to engage others independently, to be assertive, and hence their ability to operate as arguers and be accepted as reasoners.

Transgressing feminine modes can be liberating and exhilirating, making the assertiveness of argumentation and even its tendency toward aggression both exciting and deeply empowering for many women (Burrow, p. 242). Perhaps most radically transgressive, then, are fallacy labels because wielding them provides an authority to say "no" and to silence that women and others who are socially marginalized rarely receive (Hundleby 2010). However, transgressing gender norms is tough going, and women arguers regularly do not gain the same uptake as men when they adopt behaviour associated with masculinity. When women defy gendered standards of feminine, polite passivity, they initially tend to be viewed as merely requesting an active, authoritative roleespecially in expert discourse. If not prima facie excluded, women are denied the responses that men receive, and pro tanto, seem to be speaking out of turn or continuously entreating to argue (Kukla). The presumptive exclusion of women from argumentation becomes clear as dialogues play out, despite specific individuals' conscious good intentions to respect and include each other. ${ }^{3}$ For instance, regardless of discussants' perceptions and good will, women are interrupted much more often than men - even by other women, and their suggestions ignored unless repeated by a man. The effective entreaty for permission to speak, manifest for instance in expecta-

\footnotetext{
${ }^{3}$ Kukla's attention to the material context of social effect makes her approach of dysfunctional speech acts better able to account for the possibile self-deception of the audience than approaches that adhere to J.L. Austin's attention to the intentions of the audience.
}

(C) Catherine Hundleby. Informal Logic, Vol. 33, No. 2 (2013), pp. 238-262. 


\section{Catherine Hundleby}

tions that women and people of colour will smile, undermines their full participation in argumentation.

The regular phenomenon of men aggressively asserting their authority over women in matters where the particular woman has objective expertise, or in regard to women's issues, has recently gained the humorous nickname "mansplaining" (Rothman). The term emerged from a series of articles beginning with Rebecca Solnit's "Men Who Explain Things," which includes the following anecdote:

I was in Berlin giving a talk when a writer friend invited me to a dinner that included a male translator and three women a little younger than me who would remain deferential and mostly silent throughout the meal. Perhaps the translator was peeved that I insisted on playing a modest role in the conversation, but when I said something about how Women Strike for Peace, the extraordinary, little-known antinuclear and antiwar group founded in 1961, helped bring down the communist-hunting House Committee on Un-American Activities, Mr. Very Important II sneered at me. The House committee, he insisted, no longer existed in the early 1960s and, anyway, no women's group played such a role in its downfall. His scorn was so withering, his confidence so aggressive, that arguing with him seemed a scary exercise in futility and an invitation to more insult. I had written a book that drew from primary documents and interviews about Women Strike for Peace. (p. 2, emphasis added)

Mansplaining, while about the gendering of expertise and general discursive and authority more than politeness specifically, sometimes illustrates how women's polite assertions receive aggressive responses from men that women cannot effectively return.

Mere participation by women counts as unacceptably aggressive and rude. "Giving good arguments, speaking with confidence, and otherwise behaving in ways that would count as "playing well" if we were already recognized as playing can come off as arrogant and off-putting" (Kukla, p. 11). Such discursive failures of agency that track and reinforce social disadvantage amount to "discursive

(C) Catherine Hundleby. Informal Logic, Vol. 33, No. 2 (2013), pp. 238-262. 
injustice," according to Rebecca Kukla. A loss of control over our speech acts arises from the inability to mobilize social conventions, such as those of adversarial argumentation, and can result from norms of politeness that deny women - and other subordinatespolite adversarial roles. Should they explicitly assert a place in argument then the dilemma becomes manifest, as women become perceived as harsh, bitchy, defensive, "dragon-ladies", Sylvia Burrow explains (p. 255). The word "strident" almost exclusively applies to women. In sum, they appear aggressive, inappropriate, and impolite for behaviour that would be perfectly polite for men, especially among other men. On the other hand, women who decline to defend their reasoning risk appearing (to themselves as well as others) inadequate to the task, reinforcing the perception that they are not competent arguers. The gendered flow of polite discourse can prevent women from acting as fully fledged arguers whether or not they intend to embody stereotypes of white, able-bodied, middleclass, heterosexual, Euro-American femininity, and leaves women in a double-bind (Frye).

What constitutes politeness in argumentation reflects the dominant culture's masculine homosociality: the not-specificallysexual bonding between men that may involve seeking, or enjoyment of, or preference for the company of other men. Insofar as men control all sorts of power and resources, including intellectual stimulation and with the notable exception of paternity, men can receive most of what they need or even want from each other (Lipman-Blumen, p. 16). Less substantial benefits accrue from women's homosociality. However, both men and women may find it easier to operate in same-sex groups in which others' behaviours are more predictable and less complicated by heteronormative tensions between the genders-e.g., how to draw the line between friendliness and inappropriate flirtation. Women's derivative status in social discourse impedes their social interaction with men especially in competitive contexts that resonate with male homosociality as in the case of much argumentation and perhaps especially in the discipline of philosophy (Rooney 2010). 
Therefore, the assumption by Govier and Walton that politeness can eliminate unnecessary aggressiveness does not stand up to scrutiny. The gendered quality of politeness disadvantages and even disqualifies some arguers via differentially gendered measures of aggression. What counts as an adversarial or aggressive violation of etiquette depends a good deal on the arguer's perceived gender. Norms of politeness may even demand men's aggression and adversariality, for instance in a playful exchange of insults, or a hearty slap on the back. Adversarial discursive modes will in turn exclude certain people whose social roles do not permit polite rough-play, and women's efforts to engage in argumentation will go unrecognized or seem disproportionately rude. Grice's conversational maxims may not be specific enough to alleviate the gendering of politeness because of the open-endedness of their terms, e.g., "adequate evidence," "prolixity," and "informative as is required." Formal systems of discursive etiquette such as Roberts Rules, even when adversarial hold out more promise because they supersede informal systems of politeness and have greater specificity than Grice's maxims. Likewise, some women find the adversarial culture of philosophy liberating to the extent that it authorizes their transgressions of the usual politeness norms.

The exclusiveness of polite aggression may reflect general social privilege (of the archetypal white, able-bodied, middle-class, heterosexual, Euro-American man) or be more specific to masculinity as a form of domination (Burrow). Either way, it sanctions aggressive behaviour, including adversarial discourse and argumentation, from those otherwise currently advantaged, condoning their dominance through aggression. Excluding from acceptable aggression women and others who violate the social categories that define politeness helps to perpetuate existing social divisions and maintain a power structure defined by aggression (Moulton). Women may avoid taking feminist positions or identifying as "feminist" in mind of being perceived as angry or unpleasant and so remain or become further disenfranchised. Likewise people in the working class avoid behaviour that is "asking for trouble." Gays, lesbians, and people of colour may decline their rights for

(c) Catherine Hundleby. Informal Logic, Vol. 33, No. 2 (2013), pp. 238-262. 
fear that acquiring any attention may entail violence and persecution; the disabled may simply not wish to waste their time given the likelihood of being ignored.

\section{Controversy, coercion and rationality}

Even in wealthy countries benefitting from centuries of feminism, merely participating in discourse may be controversial for women:

Most women fight wars on two fronts, one for whatever the putative topic is and one simply for the right to speak, to have ideas, to be acknowledged to be in possession of facts and truths, to have value, to be a human being. (Solnit, p. 3)

Controversy clings to women who aspire to status of human beings or rational agents even more in other cultures and for women living under intersecting forms of oppression, such as race, class, and ability. Aggression and opposition toward existing situations, individual practices, institutional policies and structures, etc., construct feminist identity and epistemology in specific ways (de Lauretis; Collins, pp. 8ff; Sandoval; Hundleby 1997). The controversies surrounding and within feminism thus might benefit from better understanding of adversarial argumentation. Adversarial structures of controversy may allow space for the development of non-coercive standards for persuasion that involve a negotiable rationality.

Feminism is intrinsically controversial, drawing attention to problems with institutions, including frameworks for thought and action, and working for change in the surrounding culture. Feminist political progress demands adversarial engagement that politeness restricts from some of those, notably women, whose interests demand change. Articulating feminist adversarial orientations thus can be aided by argumentation theory. Feminism and other liberatory projects need an effective account of controversy and tools for addressing it because their nature involves controversy: fighting for women's rights, for fairness and equality; demanding change.

(C) Catherine Hundleby. Informal Logic, Vol. 33, No. 2 (2013), pp. 238-262. 


\section{Catherine Hundleby}

Feminism produces a wealth of internal disputes and controversies too, such as over the significance of pornography and regarding the value of feminine qualities associated with mothering. Opposition comes as part of the package of working for change. While feminists pioneered explicitly collaborative research methods, they also came quickly to recognize that criticism must be involved at various stages as understanding develops. More than sharing experience was required by the innovative consciousnessraising groups of the 1960s and '70s, who stressed the affirmation of lived experience and provide the historical and practical basis for much feminist methodology. The development of such concepts as "sexual harassment" and "marital rape" required criticism and challenges to personal experiences-including self-blame and resignation, in order to shed light on the larger political significance of those experiences (Wylie).

Govier's concern with controversy dovetails with political philosopher Chantal Mouffe's argument that democratic engagement depends on adversarial or agonistic processes:

Mobilization requires politicization, but politicization cannot exist without the production of a conflictual representation of the world, with opposed camps with which people can identify, thereby allowing for passions to be mobilized politically within the spectrum of the democratic process. (Mouffe 2005, pp. 24-25)

Mouffe argues that the intrinsic adversariality of politics demands agonistic structures be built into political systems. ${ }^{4}$ Resistance to the fundamental human need to define ourselves and identify in terms of friends and enemies makes our political structures dysfunctional. Although social identity does not concern Govier, who defends an individualist adversariality, holding between particular

\footnotetext{
4 Argumentation theorists may find rich resources in the related literature on feminism and citizenship. For instance a special issue of The Feminist Review addresses "Citizenship: Pushing the Boundaries" (Eds. Helen Crowley, Gail Lewis, Pnina Werbner and Nira Yuval-Davis, 57, Autumn 1997).
}

(C) Catherine Hundleby. Informal Logic, Vol. 33, No. 2 (2013), pp. 238-262. 
persons and between their ideas, she offers Mouffe and feminists a model of how agonistic reasoning can be rational.

Adversariality may entail winners and losers. Thus eristic discourse can reinforce existing (just or unjust) power relationships and undermine cooperative and egalitarian modes of arguing, especially when some participants have extra experience and license with aggressive techniques. Those with the power tend to have greater resources, anyway, even when in the wrong. Eristics may also suppose a radical opposition between truth and falsity (Cohen), leaving no room for constructive uncertainties or sensitivity to new evidence, and so subvert epistemic goals (Rooney 2010). One possible value remains in that eristic exhibitions, such as formal debates, can serve the purpose of allowing the audience to make up their minds even when the arguers have no intention of altering their own views (Kock).

In practical contexts, we must choose our argumentative goals with care, avoiding the temptations of coercive force. Some argumentation theorists maintain that any persuasion, even rational persuasion, can be coercive and so not an adequate standard or goal for argumentation. Govier counters that an arguer does not pin the audience up against a wall, in even a figurative sense (p. 50). Rational argumentation employs "considerations ... supplying evidence or grounds that make a claim seem more believable because of a cogent connection between that claim and the claims cited as its support" (p. 45). That the audience might accept the line of reasoning receives motivation from hope, not aggression (p. 50).

The believability or persuasiveness thus depends on cogency; and in turn "cogency" receives recursive support from "rationality":

An argument is cogent when its premises are rationally acceptable and relevant to its conclusion and when, considered together, they provide good or sufficient grounds for that conclusion. (Govier, p. 46) 
Cogency leans on rationality (of the premises), the persuasive force that helps define it; yet it also demands relevance, and good or sufficient grounds holding between the premises and the conclusion. Thus, leaving aside what may be the independent criteria for evaluating grounds (and perhaps relevance), one finds at least one element in cogent argumentation for which further reasons can be sought: the rationality of premises (and perhaps their relevance).

The rational element of a cogent argument may be fleshed out through sub-arguments or replying to possible objections, a dimension of argumentation that Ralph Johnson describes as the "dialectical tier" (Govier, p. 46). Rationality remains subject to judgment, and so I suggest still may be coercive should the processes of negotiation supporting that judgment involve coercion. The possibility that a judgment could be coerced may sound odd to those unfamiliar with feminist epistemology. Reasoning has complexities that include historical patriarchal baggage (Lloyd; Rooney 1991, 1994) and unconcious social bias that recent psychology reveals to hold sway especially when evaluative terms are not clearly defined. These are not conscious views about domination, or even about ancillary cultural adversariality, but nonetheless these assumptions can powerfully distort decision-making. Participating in the adversarial discourse of Johnson's dialectical tier may for many women demand contravening the tacit gender hierarchy (and perhaps other hierarchies), and risk complete exclusion. As we have seen above, politeness will not help.

Admittedly, the room Govier allows to contest and constructively decide what counts as rationality may prevent the concept of rationality from being another tool (along with politeness) that primarily serves existing structures of rhetorical power. Rationality itself can be controversial. ${ }^{5}$ Govier's attention to controversy pro-

\footnotetext{
5 Govier's separate discussion of how rationality operates in critical thinking appeals to judgment in a way that seems to lack normative force, as Harvey Siegel argues (2004, Rationality and judgment. Metaphilosophy 35(5): 597-613). His account of rational thought as coherence with rules, including unrecognized rules, while intended to account for individual thought, might also define rational
}

(c) Catherine Hundleby. Informal Logic, Vol. 33, No. 2 (2013), pp. 238-262. 
vides the political edge to her philosophy of argument: she insists on controversy's desirability, and its dependence on adversarial relationships. Controversies depend on there being more than one view, each being held in rejection of the others and sustained by arguing against those who hold the other views; they are oppositional in requiring one person to disbelieve another's claim. Such "minimal adversariality" she argues is necessary for practical politics under democracy, which demands more than tolerant regard. People who hold differing views engage and attempt to persuade each other and their representatives on matters of policy and governance.

Govier's account of controversy helps to show the broad value of feminist discourse. Adversarial argument feeds democratic politics, and may be rational at the core and non-coercive: "the existence of controversy is a healthy thing in many contexts, and if controversy implies a degree of adversariality, then perhaps some modest adversariality is acceptable in the interests of critical thinking and lively debate" (p. 51).

\section{The need for minimal adversariality?}

Sliding into adversariality can be difficult to avoid in a culture that prioritizes masculinity and aggressiveness, and conflates the two; the importance of adversariality to democratic politics complicates this still further. Yet for Govier, adversariality has significance beyond its function as a social means to benefit controversy and agonistic politics; it has a fundamental role in human reasoning and philosophical methods. Govier's view that reasoning requires internal debate has initial plausibility. We certainly do argue in our heads. "A person may critically reflect on and appraise her own thinking, thus embracing an internalized adversariality which is not negative" (p. 10). Yet thought and argumentation do not depend on

persuasion better than Johnson's adversarial dialectical tier. However, exploring that option is beyond the scope of this paper.

(C) Catherine Hundleby. Informal Logic, Vol. 33, No. 2 (2013), pp. 238-262. 


\section{Catherine Hundleby}

recognizing the opposite perspective held by even an imaginary adversary.

Govier provides two different explanations of minimal adversariality. On the one hand it involves opposition to other views, a specific psychological attitude that emerges in what she calls "Deep Adversariality."

1. I hold X.

2. I think that $\mathrm{X}$ is correct. (Follows from 1.)

3. I think that non-X is not correct. (Follows from 2.)

4. I think that those who hold not-X are wrong, or are making a mistake. (Follows from 3.)

5. Should I need to argue for X, I will thereby be arguing against not-X (?)

6. Those who hold not-X, are, with regard to the correctness of $\mathrm{X}$ and my argument for $\mathrm{X}$, my opponents. (?) (Govier, p. 244)

Most of these steps seem questionable. Govier acknowledges there may be some doubt starting with (5) and Phyllis Rooney (2010) argues that it is wholly unnecessary. My central concerns are with how this process is supposed to get off the ground, in steps (1)-(3) which may be necessary for critical thinking in some sense, but not for thinking itself, as Govier would have us believe.

The epistemological leap to (2) demands a self-reflection not part of the original doxastic attitude in (1). We believe all sorts of things at any given time without consciously recognizing them as beliefs, nevermind evaluating them. Such awareness may be forced by argumentation but that is part of the value that argumentation can add to thought: dialectical exchange encourages self-reflection that we otherwise may not have.

The more serious problem with Deep Adverariality lies in the minimally adversarial move from step (2) in which a reasoner epistemologically evaluates a thought to an epistemological evaluation of that contradictory belief in step (3). Again, this demands a cognitive self-awareness that has little psychological plausibility, but this time reasoners are supposed to render judgment on proposi-

(C) Catherine Hundleby. Informal Logic, Vol. 33, No. 2 (2013), pp. 238-262. 
tions that play no part in our own belief system. This move, however logically sensible, seems on any regular basis to be beyond our finite cognitive capacities. It describes "critical thinking" that provides the important exception to the rule of unreflective thinking.

Govier's other argument for the necessity of minimal adversariality has more modest terms, occurring when one "openly acknowledges the actuality or possibility of disagreement or doubt" (p. 47). Recognizing the "possibility of disagreement or doubt" may be part of reasoning - accompanying anything more solid than a faint glimmer of thought - but need not entail entertaining contradictory propositions as she argues. Disagreement or doubt may merely involve contrary possibilities, for instance. Say that I think it's cold outside and you think it's beautiful out, and perhaps we are both right. Or we might both be wrong, or only one of us be right. Any of these sorts of logical relationship might undergird my doubt or the disagreement may be irresolvably incoherent, say if we understand terms in different ways. Doubt and even disgreement need not involve considering contradictions and can take the forms of open-mindedness and exploration, compiling data, or casting about for further information. Those who do not agree and who are thus subject to persuasion may be undecided, tentative, or even have suspended their belief or disbelief. So may anyone be when entering into discussion and attempting rational persuasion. The possibility of disagreement or doubt intrinsic to argumentation need not entail belief in the wrongness of the contradictory of one's position.

Disagreement and doubt may not depend on wrongness or contradictories at all, and yet still be the basis for openness to rational persuasion, and so foundational to argument. We may pitch in together to develop shared understanding or anticipate how things pan out under a specific circumstances. These modes of thinking provide the grist for the mill of critical thinking and testing. Although scientific testing may depend on abductive reasoning, comparing opposing lines of thought, not all reasoning demands competitive inference to the best explanation and its logic of competi- 


\section{Catherine Hundleby}

tion. The lines of thought have to come from somewhere. Even in science, an explanatorily adequate or merely interesting account of the evidence may be our only goal. Consider how people, including scientists, sometimes begin their interjections with "so...," suggesting a collaborative rather than an adversarial intention.

I may aim to persuade you because you are not yet convinced - of the value of dogs for household safety, for instance. Likewise, we argue without disputing a claim when we receive education. The explanation to a student of what makes water expand when it freezes persuades that student rationally that the ice-cube tray may overflow. Instructors even play at not knowing in order to elicit student collaboration in learning, a technique famously described as the Socratic method. In many other cases it is true that none of the arguers has sorted out our beliefs on the topic and we may explore the information together, pooling it.

These examples all support Rooney's suggestion that we may "argue with" people without arguing against them (2010), and feminists have developed a range of practices for reasoning collaboratively. The collaborative exchanges of reasons that I have argued may be means for rational persuasion play central roles too in science and other arenas that depend on the division of epistemic labour. A physicist may build equipment for a chemistry experiment, and a statistician do the calculations. Each contributes to the development of an argument about some phenomenon in chemistry and may have to persuade the others by way of argument that the techniques applied will do the job. However, there is no opposition to the techniques or claims of expertise, only inadequate understanding that can be overcome by sharing some of the expert or testimonial evidence. These non-adversarial practices deserve to count as forms of argument, and argumentation theorists such as Govier seem to deny them that status only because they presume that argumentation must be adversarial.

(C) Catherine Hundleby. Informal Logic, Vol. 33, No. 2 (2013), pp. 238-262. 


\section{Idealized arguments and abstract adversaries}

The problems I've identified with Govier's account of adversarial argumentation seem to lie in its idealization, a tendency in philosophy that Charles Mills (2005) argues undermines a theory's effectiveness. Despite the intention of Govier and others to account for real reasoning practices, idealization or ideal theory persists in informal logic. While all philosophy may be normative and ideal in a generic sense, the type of abstraction and its degree may impede philosophers' ability to address concrete problems. Misguided abstraction can make our ideals too idealized or idealized in the wrong ways. Failing to account for how gendered communication practices including politeness affect norms of argumentation and for human logical frailty makes Govier's picture of the argumentative adversary problematically abstract and idealized.

Philosophers must abstract away from concrete situationswhether epistemic, ethical, or argumentative - in order to develop ideals in the broad philosophical sense of norms. "Abstraction is something of a relative and situated notion, as when we abstract from some of the contextual specifics or saliencies of a given situation and not others" (Rooney 2010, p. 215). So we must take care not to abstract away from what we recognize to be problems demanding attention. A pitted or cracked surface - due to natural variation or normal wear and tear, cannot be modelled well by a frictionless plane, though that model may account quite well for a teflon-coated plane suspended in a vacuum (Mills, p. 167). Likewise, adversarial logic may suffice to characterize controversies but be wholly inadequate for other types of argumentation, and even aggravate their difficulties.

Opposition has limited benefit as an orientation for rational persuasion. The oppositional mode appears universally productive only because the adversaries we have in mind are abstract: subject to identical norms of politeness and with no limits on time or cognitive capacity, such that they can appreciate and account for the logical implications of their beliefs. Idealized social ontology, idealized capacities, and silence on oppression are among the charac-

(C) Catherine Hundleby. Informal Logic, Vol. 33, No. 2 (2013), pp. 238-262. 


\section{Catherine Hundleby}

teristic aspects of idealized theory, suggested by Mills. These three can be found in Govier's argument that we can and should keep adversariality a necessary minimum.

The idealized social ontology of liberal atomic individuals in contemporary moral and political theories, Mills argues, abstracts away from the realities of "structural domination, exploitation, coercion, and oppression" (p. 168). Those concrete forces create hierarchical roles and identities, such as the gendered quality of politeness that Govier neglects. Likewise, every major approach to argumentation theory ignores the role of the arguers themselves, allowing the agents of argument to recede into the theoretical background, explains Dale Hample (2007). Argumentation theorists generally idealize social ontology by assuming the text of an argument fully represents "whatever we need to know about arguers' motivations, assumptions, knowledge, reasoning, and feelings" ( $\mathrm{p}$. 166).

Govier assumes idealized capacities by suggesting that reasoners must (and so can) hold multiple reflective views on their own understandings: the steps proceeding from (1) to (3) in her proposal for Deep Adversariality. While those steps sometimes might be possible for a reasoner with a good deal of leisure, they cannot be standard for cognizers with limited time, or lacking the opportunity for reflection, never mind training in logic or reasoning. Such privileges cannot operate as the base line for reasoning.

She passes up opportunities to address oppression, gesturing toward it only by mentioning the difficulties of feminine discourse in the way Mills describes as typical for idealizing philosophers (pp. 168-169). Govier's neglect of the deep social patterns prevents her from recognizing how oppression pervades social institutions from formal organizations such as schools and the law to informal institutions such as politeness, marriage, and even the discipline of philosophy. Oppression shapes the people in those institutions and influences their argumentation practices, and the reception of their arguments. Even without ancillary adversariality, and imagining that politeness were effective, adversarial practices typical of the discipline of philosophy and perceived as "free and open" perpetu-

(C) Catherine Hundleby. Informal Logic, Vol. 33, No. 2 (2013), pp. 238-262. 
ate both implicit and explicit social biases, including those that follow lines of gender, class, and race. Thus "epistemic injustice is likely to be exacerbated in skepticism-informed argumentative exchanges where minority members, whose experiences and claims are likely to be given less credibility, are thereby assigned greater burdens of proof" (Rooney 2012, p. 319).

Govier stops short of idealizing the cognitive sphere, the fourth marker of idealization suggested by Mills (p.169), insofar as her attention to ancillary adversariality and distinction of it from minimal adversariality points to the complexity of argumentation's social context. At the same time, the complications of ancillary adversariality and the inadequacy of politeness indicate that arguers may resist the norm of rational persuasion that she defends. She thus does not ignore exceptions, and so seems to avoid the fifth marker of idealization (Mills, p.181). Govier's work outside of argumentation theory on political reparations further indicates an intention for theory to account for existing problems.

Yet the exceptions to the norm of rational persuasion may be fostered by social roles such as masculine gender that allow for polite aggression and heighten the burden of proof for those on the social margins, factors not addressed by Govier. The distinction of politeness from adversarial rudeness itself idealizes the difference between argument and quarrel, ignoring the multiple connections providing various forces that cause arguments to degrade into quarrel.

Govier's abstract arguer has qualities distinctively resonant with white middle-class able-bodied heteromasculinity. Not only do we associate adversariality with such men to the effect that women (at least) receive disproportionately negative sanction for oppositional behaviour or even uttering contrary opinions. By excluding or extracting out collaborative contexts from our model of argumentation we assume that no argumentation goes on during learning, one of the most lively and commonplace arenas for sharing reasons with others and inviting inferences from each other, and one typically governed by women. So the abstract arguer marginalizes both women and children, or imposes upon them an ad- 
versarial model that neglects the contexts and forms that their reasoning often takes.

\section{Conclusion}

Adversarial modes of reasoning have neither foundational nor over-riding value as means for rational persuasion. Other forms of social engagement and shared reasoning practices deserve recognition as forms of argumentation, from the most established views shared through persuasive teaching to the most daring explorations achieved through the division of cognitive labour in science. These involve rational persuasion among people who may disagree or doubt a proposition under consideration, but who need not have contradictory opinions. I suspect we'll be hard pressed to find a good discursive definition of argument that requires adversariality without being ad hoc, and that would make circular any argument for the necessity of adversariality.

Despite the problems with Govier's position that politeness can reduce adversariality to a necessary minimum, her account of the value of adversarial reasoning at the social level retains a vital significance for feminism and social progress. Feminists and other arguers need tools for working through situations of minimal adversariality, for keeping the minimum from becoming aggravated and blooming into a culture of hostility, and perhaps for recognizing when argument will not suffice as a means for addressing conflict. Whether we need to institutionalize adversarial practices as Mouffe argues, progress of one kind or another depends on change and requires some opposition to the current state of affairs and the reasoning that supports it. Govier's distinction between minimal and ancillary adversariality opens up space for discussing the different forms and levels of adversariality. Developing this further could help us figure out how to minimize harmful adversariality and when the minimal adversariality constituted by different opinions is productive, politically and epistemologically.

(C) Catherine Hundleby. Informal Logic, Vol. 33, No. 2 (2013), pp. 238-262. 
Mills advises, "the best way to bring about the ideal is by recognizing the nonideal, and...by assuming the ideal or near-ideal, one is only guaranteeing the perpetuation of the nonideal" (2005, p. 182). We must know how aggression works and how it takes hold in order to minimize it and allow rationality to play its intended role. Empirical studies of aggression tend to conflate argumentation with aggressive communication (Rancer and Avtgis) and yet research also shows that training in argumentation decreases verbal aggression such as swearing (Hamilton and Tafoya). The empirical understanding concerning aggression may be irreducibly complex, as Helen Longino argues, but argumentation theorists will get better answers to our questions about aggressive arguers if we consider the available evidence.

Rationality remains an ideal or paradigm for reasoning, and when we make it open to negotiation, as does Govier, we may help to avoid the regressive pitfalls of ideal theory. However, much remains to be said about the constitution of that rationality, or how it can be negotiated in argumentation, and how it might be controversial and in some sense adversarial without playing into existing masculine norms of adversariality. Govier expects politeness to do too much work, to cleanse argumentation of the aggression implicit to masculine strategies for politeness in the dominant culture. While feminists and all fair-minded people need adversarial strategies for argumentation, we must not assume that rationality can provide a transparent neutrality to guide adversarial processes any more than we can assume that of politeness. It remains to be seen whether rationality might provide the means for argumentative persuasion that enables respect and acknowledges difference in the way Govier maintains. Rationality might ground a more inclusive account of argument, and do the work that politeness cannot. We also might be able to transform our norms of politeness, by adopting specialized rules for particular contexts, to make them better support rationality and the adversarial discourse that reasoners sometimes need.

(c) Catherine Hundleby. Informal Logic, Vol. 33, No. 2 (2013), pp. 238-262. 


\section{Catherine Hundleby}

Acknowledgements: This paper benefits greatly from helpful suggestions from an audience at the Centre for Research in Reasoning, Argumentation and Rhetoric at the University of Windsor, including Tony Blair, Hans Hansen, Kate Parr, Bob Pinto, Chris Tindale, and Doug Walton, as well as comments from Charissa Varma and an anonymous reviewer.

\section{References}

Burrow, S. (2010). Verbal sparring and apologetic points: Politeness in gendered argumentation contexts. Informal Logic 30(3): 235-262.

Cohen, D.H. (1995). Argument is war...and war is hell: Philosophy, education, and metaphors for argumentation. Informal Logic 17(2): 177-88.

Collins, P.H. (2000). Black Feminist Thought: Knowledge, Consciousness and the Politics of Empowerment, $2^{\text {nd }}$ ed. New York: Routledge.

De Lauretis, T. (1990). Upping the anti (sic) in feminist theory. In M. Hirsch and E.F. Keller (Eds.), Conflicts in Feminism. New York: Routledge.

Frye, M. (1983). The Politics of Reality. Trumansburg, NY: Crossing Press.

Govier, T. (1999) The Philosophy of Argument. Newport News, VA: Vale Press.

Grice, H.P. (1989). Studies in the Way of Words. Harvard University Press.

Hamilton, M.A. and Tafoya, M.A. (2012). Toward a collective framework on verbal aggression: Hierarchical and antagonistic processes. Journal of Language and Social Psychology 31: 112130.

Hample, D. (2007). The arguers. Informal Logic 27(2): 163-178.

Hundleby, C. (2010). The authority of the fallacies approach to argument evaluation. Informal Logic 30(3): 279-308.

(C) Catherine Hundleby. Informal Logic, Vol. 33, No. 2 (2013), pp. 238-262. 
Hundleby, C. (1997). Where standpoint stands now. Women \& Politics 18(3): 25-43.

Johnson, R.H. (2000). Manifest Rationality: A Pragmatic Theory of Argumentation, New York: Routledge.

Kock, C. (2009). Constructive controversy: Rhetoric as dissensusoriented discourse. Cogency 1(1): 89-111.

Kukla, R. (forthcoming 2013). Performative force, convention, and discursive injustice. Hypatia, on-line preview.

Lipman-Blumen, J. (1976). Toward a homosocial theory of sex roles: An explanation of the sex segregation of social institutions. Signs 1(3), Women and the Workplace: The Implications of Occupational Segregation: 15-31.

Lloyd, G. (1984). The Man of Reason: "Male" and "Female" in Western Philosophy. University of Minnesota Press.

Longino, H.E. (2001). What do we measure when we measure aggression? Studies in the History and Philosophy of Science 32(4): 685-704.

Mills, C.W. (2005). "Ideal theory" as ideology. Hypatia 20(3): 165-184.

Moulton, J. (1983). A paradigm of philosophy: The Adversary Method. In S. Harding and M.B. Hintikka (Eds.), Discovering Reality, pp. 149-164. Boston: D. Reidel.

Mouffe, C. (2005). On the Political. New York: Routledge.

Nelson, L.H. and Nelson, J. (1995). Feminist values and cognitive virtues. Philosophy of Science Association 1994, 2: 120-129.

Rancer, A.S, and Avtgis, T.A. (2006). Argumentative and Aggressive Communication: Theory, Research, and Application. Thousand Oaks, CA: Sage.

Rooney, P. (2012). When philosophical argumentation impedes social and political progress. Journal of Social Philosophy 43(3): 317-333.

Rooney, P. (2010). Philosophy, adversarial argumentation, and embattled reason. Informal Logic 30(3): 203-234.

Rooney, P. (2004). Feminism and argumentation: A response to Govier. Informal Logic at 25. Windsor, ON: Ontario Society for the Study of Argumentation (CD-ROM). 


\section{Catherine Hundleby}

Rooney, P. (1991). Gendered reason: Sex metaphor and conceptions of reason, Hypatia 6(2): 77-103.

Rothman, L. (2012). A cultural history of mansplaining. The Atlantic. November 1.

http://www.theatlantic.com/sexes/archive/2012/11/a-culturalhistory-of-mansplaining/264380/. Accessed December 14, 2012.

Sandoval, C. (1991). US third world feminism: The theory and method of oppositional consciousness in the postmodern world. Genders, (10): 1-24.

Solnit. R. (2008) Men who explain things. Los Angeles Times, April 13.

http://articles.latimes.com/2008/apr/13/opinion/op-solnit13. Accessed December 14, 2012.

Walton, D.N. (2010). Why fallacies appear to be better arguments than they are. Informal Logic 30(2): 159-184.

Walton, D.N. (2007). Dialogue Theory for Critical Argumentation. John Benjamins.

Walton, D.N. (1996). Argumentation Schemes for Presumptive Reasoning. Mahwah, NJ: Lawrence Erlbaum.

Wylie, A. (1992). Reasoning about ourselves: Feminist methodology in the social sciences. Women and Reason, pp. 225-244. Ann Arbor, MI: University of Michigan Press.

(C) Catherine Hundleby. Informal Logic, Vol. 33, No. 2 (2013), pp. 238-262. 